\title{
Reconstitución inmunológica mediante trasplante medular en un paciente portador de inmunodeficiencia combinada severa
}

\author{
Benito González M. ${ }^{3}$; Patricia Dal Borgo A.2; Esperanza Marzouka B.2; \\ Soledad Gotoy P. ${ }^{3}$
}

\section{Bone marrow transplantation for severe combined immunodeficiency}

\begin{abstract}
A o month old boy wilh severe combined immunodeficiency disease wos treated successlully with o bene marrow ranspiantation (BMT) from his HLA-ienical dizygotic fomale wwin. Development of immune lunctions was achieved within 3 months with full reconstitulion of T-and B.lymphocytomedialed responses. The donor was Iranslused with irrodiated self Fresh whele blood, she showed good tolerance tor the procedure, without complications ond was discharged 24 hours larer without changes in her hematological paramelers. The recepter showed clinical and bacleriological cyidencos of disseminaled intection by bacilius of Calmetie-Guerin belase and after bone marrow transplantation, and was treated witin rifampicine, isoniazid, ethambuta. The elinical presentelion of $\mathrm{BCG}$ intection wos like that scen in similar cases and mimiked some aspects cf local reactions at BCG voccination sile that have been described in parients with Kawasaki disease. No condilloning irealment was given to the patlent and a mild gratt versus host disease was seen one month atter bone marrow infusion, consisting of rash, hepolomegaly, thrombocylopenia and increased serum activity of liver enzymes. He was successfully liealed with hydrocortisone and prednisone lor threc months. One year atler bone mallow irnsplantation the patient remains clinically well and free of ony significant infection.
\end{abstract}

Key words: severe combined immunadeficiency, disseminated Bacillus Colmette-Guerin, bone masow transplanlalion. Kawasaki disease.!

La inmunodeficiencia combinada severa (IDCS) constiluye un grupo hetcrogéno de afeccioncs caracterizadas por compromiso importante de los mecanismos de defensas mediados por linfocitos $\mathrm{T}$ y $\mathrm{B}$, que se manifiesta por mayor susceptibilidad a infecciones, cspecialmente oportunistas, provocando la mucrte de cstos pacientes antes de cumplir un anto de edad ${ }^{1}$. Se han definido diferentes mecanismos patogénicos cn la IDCS, entrc cllos alteraciones genéticas, enzimáticas y defectos en las membranas celulares $^{2}$. En nuestro país estos enfermos suclen tener sobrevida no superior a $\operatorname{los} 12$ meses de edad y los pacientes publicados han muerto principalmente a causa de diseminación de la vacuna

1. Unidad de Inmunología, Ilospital I uis Calvo Mackenna.

2. Unidad de Hematología, Jiospital Luis Calvo Mackena.

3. Tecnólogo Médico. Unidad de Inmunología, Hospital Luis Calvo Mackenta.
$\mathrm{BCG}^{3}$, lo que ha constituido un scrio tropiczo on la planificación de tratamientos destinados a corregir estas inmunodeficiencias. En otras naciones, el bajo porcentaje de niños que reciben dicha vacuna permite estudiar adecuadamente a los pacientes antes que presenten la aludida complicación ${ }^{4}$.

Se han efectuado diversos intentos terapéuticos destinados a corregir las anormalidades inmunológicas de la IDCS. En $1968 \mathrm{sc}$ llcuó a cabo el primer trasplante medular (TM) en un niffo afectado, con reconstitución total de su sistema inmunológicos. Desde entonces, en diferentes centros se ha demostrado la efectividad del procedimiento con sobrevidas cercanas a $80 \% \%^{6}$. Los resultados obtenidos han revelado tambien que la reconstitución inmunologica sc mantiene a lo largo del tiempo, estableciéndose un estado de quimera entre las células del donanie y el recep10r. En forma diferente al TM efectuado a enfermos leucémicos no se ha requerido, en algunos 
casos, de terapias condicionantes asî como lampoco de medicación inmunosupresora.

Nucstro propósito es describir el primer easo de IDCS sometido a trasplante medular en nuestro país. EJ buen éxito oblenido, con normalización completa de los mecanismos defensivos c incorporación a una vida normal después de 6 meses de la intervención, permite recomendar este tratamiento en otros pacientes portadorcs de csta forma de inmunodeficiencia.

\section{Paciente y Métodos}

Yin̄o de seis meses de edad, nacido de parto gemelar, por ccsárea, a las 38 semanas de cmbarazo, peso $2100 \mathrm{~g}$ y talla $42 \mathrm{~cm}$ al naccr. l.a hermana gemsclar pes6 $2150 \mathrm{~g}$ y su talla fue $43 \mathrm{~cm}$. Padre y madre sanos, de 29 años de edad. La madre tuvo dos bijos que fallecicron a la edades de 3 y 4 meses respectivamente, muertes atribuidas a bronconeumonias. Dutante los primeros cinco meses de vida cl paciente sufrió en dos oponunidades afecetiones pulmonares scveras, que requirieron tratamientos con antibióticos, un episudio de deshidralación debida a diarrca por Escherictia coli enteropatógena, que hízo necesarios huspitalización y tratamiento parenteral, desde la cdad de un mes; Jematitis por Condida abbicans y moniliasis bucal resistente a los iratamicnlos convencionales, y a la de tres meses mfección urinaria por $E$. coli. Initable, temperatura $38,6^{\circ} \mathrm{C}$, pălído, desmutrición severa (peso $4300 \mathrm{~g}$ ). No se palpaban ganglios periféricos. liscaso de sarrollo del 1ejido amigdaliano. Algorra deł paladar y lengua. Respiración soplante en el tercio infe. rior izquicdo y escenotes finos diseminados en ambos campos pulmonares. Dislension abdominal y as as intestinales prominentes que dificultaban la palpación del higado $y$ el bazo. Condensaciones bilaterales, imágen cardíaca nomal y silueta tímica ausente cn la radiografía de tórax. [n cl hemograma, 2800 leucocitos por man ${ }^{3}, 15 \%$ neutrófilos bacilifuremes, $12 \%$ segmentados, $15 \%$ linfocitos, $4 \%$ monocilos, hematocrito $3 \mathrm{~s} \%$, hemoglobina $9,4 \mathrm{~g} / \mathrm{dl}$, plaquetas nomales. Urocultivo $E$. $c 0$ li $>100000$ colonias por mun ${ }^{3}$. Prucbas de función renal y hepática notmales. Fosfatasas alcalinas $230 \mathrm{U} /$. Ilemocultivos negativos. Inmunoglobulinas séricas: IgG $120 \mathrm{mg} / \mathrm{dl}$ (VN $540-1200 \mathrm{mg} / \mathrm{dl}$ ), IgM $14 \mathrm{mg} / \mathrm{dl}\langle\mathrm{VN}=50$ a 120$)$, IgA no cuantificable (VN $30-$ 89). PPD intradérmico negatjvo. Subpoblaciones linfocitarias (mediantc antisueros monoclonales): $\mathrm{CD}_{3} 4 \%$ (VN: $55.75 \%$ ). $\mathrm{CD}_{4} 2 \%_{0}$ (VN: 36-43); $\mathrm{CD}_{6}=2 \%$ (VN: 19-29). La prucba de blaslogénesis para capacidad probiferativa de los linfocitos dio indice de estimulación de $1200 \mathrm{cpm}$ (VN: $>70000$ cpm). Las concentraciones séricas de adenosina deaminasa, complemento $\left(C_{3}\right.$ y $C_{4}$ y actividad global) lueron nomales y los titulos de ísohemaglutininas y anticuerpos $\mathrm{V} l \mathrm{H}$ negativos.

Comprobada la inmunodeficiencia combinada severa se indicó terapia profilácrica para la disemnación $\mathrm{BCC}-\mathrm{cor}$ tifampicina $\mathrm{e}$ isoniacida- $\mathrm{y}$ la infecciōn por Pneumocystit carinä œon cotrimoxazol-, como también tratamienly de candidiasis sistémica con anfotericina y cobertura con antibióticos de amplio espectro.
La tipificacion del sistema Ill $A$ del pacicnte y su farnilia mustró idenlidad genćtica entre ambos gemelos, confirmada con analisis de cultivo mixto. Los haplotipos curtespondicron a las combinacioncs A1; A28: B5: B18: Dr2: Dr3. La evaluación inmunológica de la donante fue nonnal y los títulos serologicus para citumegalovins, virus lipsteinBarr, loxoplasmosis, enfermedad de Chagas, bepatitis B $y$ virus de inmunodeficiencia adquirida, fucron lodos negativos-Antes del trasplante medular se cxtrajo a la donante $300 \mathrm{ml}$ de sangre que fueron irradiados con 3000 tads para reparar la pérdida sanguínta del procedimicnto. A ia edad de 6 meses se realizó el trasplante medular, sin terapia previa inmunosupresora ni ciclosporina, por el tipo de afección y eludir los rjesgos de taño renal con esa droga en niños pequeños. Mediante anestesia general se obuvicror. por punción de ambas crestas ilíaças posteriores con tó́cares Jamshidj (American Phamascal), 100 cc de medula, en alícuotas de 5 a $10 \mathrm{cc}$ de médula que fueron depositadas en medio de cultivo celular esićril con heparina y luego fijtradas en mallas de acero para eliminar grumos dc grasa y espículas óscas. De esta manera se obluvo el equivalentc a $3.5 \times 10^{\circ}$ células por $\mathrm{kB}$ de peso del receptor $(95 \mathrm{cc})$, que le fueron transfundialas en una hora a través del catéter central. En las $4 B$ horas siguientes sufrió hipotensión, kaquicardia y laquipuca, que se corrigicron en $72 \mathrm{~h}$, coincidicndo con cl uso de dopamina. Al cuarto dia tuvo diarrea, distensión abdominal y comproniso del estado general, que hicieron sospechar septicemia por Clostridium difficile, por lo que se indicó vancomicina, en coincidencia con lo cual mostró franca mejoria 48 horas después, pero los cultivos fueron persistentertente negativos. Desde la primera semana mus. tró una crupción morbiliforme yeneralizada, aumento de tamaño hepático ( $3 \mathrm{~cm}$ del reborde), incremento moderado de transaminasas, leucopenia intensa, trombocitopenia de $30000 / d 1$ e hiponatremia -que se atribuyó a secreción inapropiada de homona antidiurética- todo ello sugerente de reacción de injerto versus huésped (IVH) razón por la cual se indico hidrocortisona endovenosa durante $48 \mathrm{~h}$ y luego prednisona oral $1 \mathrm{mg}$ - $\mathrm{kg}$. día. En cl curso de la mis$\mathrm{ma}$ semana se detecló intcosa induración y eritema localizados en la zona de la vacuna $B C G$, de cuya punción sc obluvicren eascum y bacilos BCG, agregándose al etambutol al tratamiento antituberculoso antes señalado. Fintre la segunda y uctava scmana de cvolución, el paciente mejoró. desaparecieron los síntomas cutáneos, persistiendo hepatomegalia dura $6 \mathrm{~cm}$ bajo el borde costal, franca neutropena (200 PMN por $\mathrm{mm}^{3}$ ) y trombocitopenia (20 000 plaquetas por $\mathrm{mm}^{3}$ ). Se agregó alimentación parenteral, gamriglobulina iv $400 \mathrm{mg}$ - kg semanal el primer mes y luego cada 15 días, en coincidencia con lo cual fue posible suspender la alimentación parenteral; la temperatura corporal se normalizs y cl paciente pudo ser trasladado de aislamiento a sala común. La hepatomegalia desapareció al tercer mes desde cl trasplante, con transaminasas tormales. Los esteroides y la gammaglobulina se suspendieron al quinto mes postoperatorio. Al año de edad pasaba $9870 \mathrm{~g}$, su talla era $78 \mathrm{~cm} y$ se mantuvo en excelentes condiciones hasta la edad de 17 meses, cuando en un control de rutiva sc encontró evidencia clínica, cintigráfica y radiológica de osteomelilis del tercio superior de la tibia lzquerda, cuya histología y cultivos mostraron que era debida a BCG. Los anátisis pars derectar compromiso sistémico han sido negativos y el paciente. después del drenaje quirúrgico, sc ha mantenido asintomático hasta esta comunicación. 


\section{Resultados}

Las principates funciones inmunológicas del paciensle fueron controladas cada is días cn el primer mes después del trasplante, y Jucgo, una vez al mes basta compnobar la reconstilución inmunologia. Para la cvaluación de la inmunidad celular se determinaron subpoblaciones lífocitarias mediante inmunofluorescencia indirecta con anticuerpos

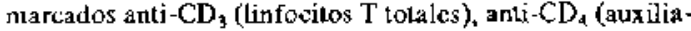
res/inductores) y anti-CD (supresores/citotóxicos). Las subpoblaciones $B$ se cuantificaron con un anticuerpo polivalente antïnmunoglobulina humana. Las respucstas proliferativas de poblaciones 'I" se probaron mediante ensayo de blastogénesis en células mononucleadas obtenidas de sangre heparinizada' y cullivadas cn medio RPMI-1640 con ant1bióticos. De la suspensión resultante sc incubó 0,1 $\mathrm{ml}$-conteniendo $1,5 \times 10^{6}$ células - en cada pocillo de microplacas recubicras con distintas concentraciones de PPD, durante 5 días a $37^{\circ} \mathrm{C}$ en atmósfera de $5 \%$ de $\mathrm{CO}_{2}$ cn estufa de culijvo celular. Dieciocho horas anles de terminar la incubación se agregó solución cstćril de 3-metil-1inidina ( $5,0 \mathrm{Ci} /$ mmole, Amersham, Arligton). Las células fueron coscchadas en papel filtro, cl contenido del isótopo incorporado por las cólulas se midió por espectófotomelría líquida de centcllco en un contador beta. Las muestras se prucesaron por triplicado, el resultado se expresó como promedio de cuentas por minuto (cpm) y desviación estándar, una vez restadas las cuenus basales (sin estumulo). E1 mismo proce. dimiento por tríplicado se efectuó para detenninar la respucsta de los linfocitos a la filohemaglutinina (PHA): después de $72 \mathrm{~h}$ de incubación con $10 \mathrm{ug} / \mathrm{ml}$ de PHA en amósfera húmeda de $\mathrm{CO}_{1}$, se agregaron 2 uCI de fimidina tritiada y las células cosechadas se sometieron a lecturas en el contador beta. La respuesta humoral se evaluó a través de las concentraciones séricas de inmunoglobulinas por inmunodifusión radial mediante sueros monoespecificos". Del mis. mo modo se midieron las concentraciones séricas de complemento $C_{3}$ y $C_{4}$. La actividad de adenosina dcaminasa séricd se detcrminó con el mćtodo colorimétrico y la técnica original de Giusti?.
Modificaciones de las subpoblaciones T. Antes del trasplante habia disminución significativa de las tres subpoblaciones de linfocitos $T$, (tabla 1), con sólo $3 \%$ de linfocitos T totales alcanzó $\left(130 \times \mathrm{mm}^{3}\right)$ y disminución global de las poblaciones $\mathrm{CD}_{4}$ y $\mathrm{CD}_{8}$. Las subpoblaciones supresoras/citolóxicas $\left(\mathrm{CD}_{8}\right)$ alcanzaron valores normales 30 días despucs del trasplante. Las cantidades totales de linfocitos $\mathrm{T}\left(\mathrm{CD}_{3}\right)$ y auxiliares $\left(\mathrm{CD}_{4}\right)$, solamente lo hicieron al cabo de tres meses de efectuado el procedimicnto. La última cvaluación de cstas subpoblaciones linfocitarias se cfectuó una vez cumplido cl año de seguimicnto y los resultados obtenidos fucron valores normales para las tres series analizadas.

Efecto del trasplante sobre la capacidad proliferativa de los linfocitos $T$. Los índices de proliferación de las células $T$ frente a un mitógeno (fitohemaglutinina) y a un antígeno (PPD) se muestran en la tabla 2. Las respuestas proliferativas a PHA aumentaron significativamente a los 15 dias de efectuado el TM, a $35000 \mathrm{cpm}, 50 \%$ de lo considerado normal en nuestro laboratorio, coincidiendo con intenso viraje tubercalínico en la segunda semana de evolución y la presencia de material caseoso en el lugar de la vacunación BCG. Los controles posteriores han demosuado valores intermedios de esumulación, aun cuando hay que tener presente que durante cse tiempo el

\section{Tabla 1}

Modificaciones de las subpoblaciones linfocitarias antes y después del trasplante medular

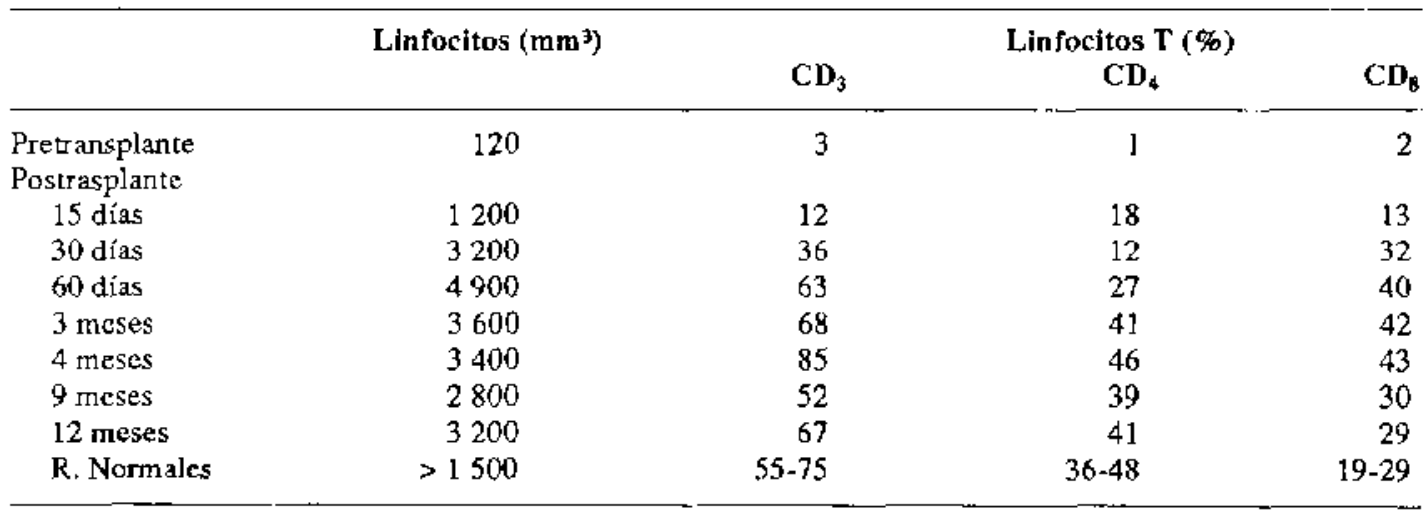


Tabla 2

Respucsta proliferativa de linfocitos obtenidos de sangre periférica estimulados con fitohemaglutinina (PHA) y PPD antes y después del trasplante de médula ósea**

\begin{tabular}{|c|c|c|c|c|c|c|}
\hline & \multicolumn{2}{|c|}{ PHA } & \multicolumn{4}{|c|}{ PPD* } \\
\hline & Basal & PHA & Basal & 25 & 50 & 100 \\
\hline $\begin{array}{l}\text { Pretrasplantes } \\
\text { Postrasplante }\end{array}$ & 1553 & 2696 & 539 & 320 & 755 & 598 \\
\hline 15 días & 738 & 34954 & 1162 & 6392 & 13294 & 13418 \\
\hline 30 días & 1230 & 35243 & 2360 & 9870 & 33260 & 67380 \\
\hline 60 días & 3877 & 20800 & 3877 & 5533 & 16663 & 23789 \\
\hline 90 días & 1540 & 40113 & 1376 & 4350 & 8342 & 11366 \\
\hline 9 meses & 1400 & 65000 & 3200 & 32220 & 36700 & 42000 \\
\hline 12 meses & 1200 & 140000 & - & - & - & - \\
\hline R. Normales & $<2000$ & $>70000$ & $<2000$ & $>15000$ & $>20000$ & $>35000$ \\
\hline
\end{tabular}

* Se ucilizaron 3 concentraciones de PPD, 25, 50 y $100 \mu \mathrm{g} / \mathrm{ml}$.

** Los resultados expresan los promedios de las cuentas por minuto obtenidas de las muestras procesadas en triplicado.

enfermo recibió esteroides, que pueden alterar los resultados de estos análisis. El último control de blastogénesis se efectuó a la edad de 1 año 6 meses, obteniéndose índices de estimulación de $140000 \mathrm{cpm}$, que se consideran dentro de los normales. La respuesta específica al PPD se caracterizó por intensa proliferación de los linfocitos a concentraciones de 50 y $100 \mu \mathrm{g} / \mathrm{ml}$ de tuberculina, que coincidió con lesiones en el sitio de inoculación de BCG y fue seguida de declinación en los índices de estimulación, cuyas tasas alcanzaron rangos normales al mes de obscrvación. Antes del trasplante dos rcacciones intradermicas de 5 UI de PPD dieron resultados negativos ( $0 \mathrm{~mm}$ induración), pero en la segunda semana de efectuado el procedimicnto hubo intensa reacción, con $15 \mathrm{~mm}$ de induración a las 72 horas y una respuesta precoz, en las 6 primeras horas, con critema -de aproximadamente $20 \mathrm{~mm}$ que disminuyó progresivamente en 24 horas. A la edad de 17 meses, cuando se indentificó un foco óseo de $\mathrm{BCG}$, la intradermorreacción tuberculínica produjo una induración de $14 \mathrm{~mm}$.

Efecto del trasplante sobre las concentracionex de inmunoglobulinas y anticuerpos séricos. Las inmunoglobulinas séricas IgG e IgM experimentaron rápida normalización, evidente tres meses después del trasplante. La IgA se mantuvo por debajo de lo normal. Los títulos de isohemaglutininas cran normales a los seis me- ses del procedimiento (1/120). El complemento sérico $-\mathrm{C}_{3} \mathrm{C}_{4}-$ no se modificó después del trasplante.

\section{Comentario}

Se describe el primer caso en Chile de trasplante de médula ósea -cn un niño afectado por inmunodeficiencia combinada severa-procedente de una donante gemelar, bivitelina de 6 meses de edad. Se obtuvo rápida reconstitución de los mecanismos de inmunidad mediados por linfocitos T y B, dentro de los tres meses siguientes, sin signos de rechazo pero con moderada reacción de injerto versus huésped. Tan favorable respuesta del sistema inmune probablemente guardó relación con la buena compatibilidad antigénica de ambos niños, lo que hizo posible hacer el trasplante sin tcrapia condicionante previa ni régimen inmunosupresor, procedimientos empleados para evitar la reacción de injerto contra huésped y el rechazo por parte del receptor, especialmente cuando no sc dan condiciones de identidad genética entre receptor y donantc.

Otros aspectos importantes para cl buen éxito del trasplante de médula en estos nif́os han sido la presencia de adenosina deaminasa y la actividad de las células NK (destructoras naturales o "natural killer"10). En nuestro paciente la 
Tabla 3

lnmunoglobulinas séricas y linfocitos B antes y despuès del trasplanic medular

\begin{tabular}{|c|c|c|c|c|}
\hline & $\underset{(\mathrm{mg} / \mathrm{dl})}{\mathrm{IgG}}$ & $\underset{(\mathbf{m g} / \mathbf{d l})}{\operatorname{Ig} \mathbf{A}}$ & $\underset{(\mathrm{mg} / \mathrm{dl})}{\lg \mathrm{MI}}$ & $\begin{array}{l}\text { LB } \\
(\%)\end{array}$ \\
\hline $\begin{array}{l}\text { Pretrasplante } \\
\text { Postrasplante }\end{array}$ & 120 & $<10$ & 23 & 25 \\
\hline 15 días & 190 & $<10$ & 52 & 28 \\
\hline 30 días & 540 & $<10$ & 72 & 30 \\
\hline 60 dias & 650 & 8 & 94 & 29 \\
\hline 90 dias & 1180 & 10 & 85 & 32 \\
\hline 9 meses & 1087 & 12 & 199 & 28 \\
\hline 12 mescs & 795 & 8 & 196 & 22 \\
\hline R. Normales & $756-1190$ & $50-128$ & $53-141$ & $18-20$ \\
\hline
\end{tabular}

actividad de la enzima era normal, mientras en otros, que carecen de ella, las posibilidades de resultados favorables con el procedimiento disminuyen notoriamente, pues en tal caso se hace necesaria una scric de manipulaciones en las cclulas del donante para efectuar el trasplante. Los niños con actividad NK muy clevada también lienen peor pronóstico que los lactantes en que ella es mâs baja, pero este aspecto no fue investigado en nuestro paciente debido a problemas inherentes a la técnica de laboratorio ${ }^{1-13}$.

La donante de médula, hermana gemelar del paciente, tenía 5 meses de edad cuando se iniciaron los estudios para el uasplante. Los riesgos potenciales para ella fucron evaluados cuidadosamente antes de someterla a la extracción medular. El Registro Internacional de Trasplante de Médula Osea (IBMTR) ha informado de nueve casos de complicaciones serias al donar la médula, dos en niños: uno, de 10 años, sufrió septicemia; otro, de 4 años, taquicardia ventricular ${ }^{14}$. En otra serie, donde diecinueve donantes eran menores de 2 afios, no se registraron complicaciones de importancia ${ }^{15}$. Estos antecedentes hacían suponer que el riesgo potencial para nucstra donante era mínimo. En efecto, no registramos incidentes y se dio de alta a las 24 horas de exiraída la médula ósea.

Nucstro grupo ha tratado tres pacientes con csta enfermedad, cmpleando trasplantes de cpitelio tímico en dos y de hígado fetal en el otro, observándose respuesta inmunológica favorable inicial, pero todos murieron antes de transcurridos dos meses desde las intervenciones, a causa de diseminación de la vacuna BCG. El paciente que se comenta tenía, al momento de efectuar el trasplante, algunas evidencias de esta complicación, como pápulas y vesículas en la cara, cierto grado de infiltración pulmonar y hepatomcgalia, que fue confirmada y tratada con rifampicina, isoniacida y etambutol en espera de la respuesta al trasplante medular, presentándose -once meses despućs- un foco residual de osteomelitis de la tibia causido por $\mathrm{cl} B C G$ que, sin cmbargo, no constiluyó problema después de haber sido drenado, dada la integridad alcanzada en su sistema inmune.

Otra complicación que suele atectar a niños somctidos a trasplantes de médula ósca cs la reacción injerto versus huésped, originada en las células del donante, que reconocen como extrañas cicrtas estruclutas del receptor, produciendo estimulación descontrolada de los linfocitos T que infiltran ciertos parénquimas, preferentemente la piel, hígado y el tubo digestivo. Este tipo de reacción cnsombrece el pronóstico y hay cicrto grado de correlación entre su intensidad y la evolución posterior. En nusstro pacientc las principales manifestaciones de la reacción ocurricron en la piel, el hígado y la sangre, pero su intensidad fue considerada leve y sólo se hizo tratamicnto con esteroides, con buenos resultados. Los estudios histológicos de la picl de niños sometidos a trasplante a causa de inmunodeficiencia combinada severa que desarrollaron rcacción de injerto versus hućsped, han mostrado cambios significalivos en la epidermis, intensa distorsión de la arquitectura celular, necrosis de 
las células basales y del cstrato de Malpighi, degencracion liquenoide de las células epiteliales, bulas intracclulares y edema prominente de las regiones intercelulares. En la biopsia de nuestro paciente, obtenida del lugar de aplicación del BCG, diez días después del trasplante, había signos muy sugerentes de dicha reacción, mientras en la zona subepidérmica los cultivos confirmaban la presencia de bacilos BCG. La explicación para esta observación es difícil, aun cuando es interesante rccordar que en niños con enfermedad de Kawasaki se han descrito lesiones critematosas en la zona de aplicación de la vacuna BCG, cuya frecuencia guardó relación con el tiempo transcurrido entre inoculación de la vacuna y edad de presentación de la enfermedad, ya que los lactantes en que el lapso fue 566 meses tuvieron mayores probabilidades de prescntar esta manifestación. Estos hallazagos sugicren una reacción semejante a la de injerto versus huésped en la erupción critematosa de la cnfermedad de Kawasaki 16 .

La rápida nomalización de las concentraciones séricas de inmunoglobulinas y anticuerpos ел este niño, confirman que cuando se trasplanta médula sin manipulación previa para disminuir el riesgo de injerto versus huésped o regímencs condicionantes en el receptor, sc normaliza más rápido la respuesta humoral del receptor. La cantidad de linfocitos B del paciente, antes del trasplante, era normal para su edad, pero estaban imposibilitados para sintetizar inmunoglobulinas. La respuesta al trasplante confirmó la importancia de las poblaciones $T$ para el buen funcionamiento de las células productoras de anticuerpos. No fue posible establecer fehacientemente la presencia de una quimera inmunológica debido a fallas técnicas en los cultivos para análisis cromosómico, pero, como lo han demostrado otros autores, cstos niños sobreviven con linfocitos provenientes tanto del donante como del receptor. Mientras las tasas circulantes de linfocitos $T$ se normalizaron precozmente después del trasplante, la capacidad funcional de ellos, evaluada en la blastogénsis, lo hace más lentamente, al cabo de varios meses.

Los resultados que se están obteniendo con el trasplante de médula ósea hacen aconsejable que nuestro país no se mantenga alejado de cstos procedimientos. Su elevado coste podría minimizarse mediante el trabajo cooperativo de las diversas especialidades involucradas. De esta manera, cl TM puede constituir una alternativa de tratamicnto definitivos para una serie de enfermedades que en la actualidad son irremediablemente fatales.

\section{Resumen}

Un paciente de 6 meses de edad, portador de una Inmunodeficiencia Combinada Severa, fue tratado mediante trasplante de médula idéntico (TM), oblenido de una hermana gemelar, bivitclina. El lactante no recibió terapia condicionante previa y tampoco terapia inmunosupresora. La evolución que sigujó al procedimiento demostró una rápida normalizaciốn de los mecanismos inmunológicos mediados por linfocitos T y B. Como complicación al TM se apreciaron diferentes manifestaciones sugerentes de reacción injerto versus huésped (GVH) la que fue controlada mediante el uso de esteroides endovenosos y orales. Un eritema en el lugar de inoculación de la vacuna $B C G$, hallazgo que no hemos encontrado cn la literatura relacionada con pacientes sometidos a este procedimiento, fuc analizado con biopsia de piel, demostrando signos locales de reacción GVH. En las estructuras profundas se pudo identificar material caseoso y los estudios bacteriológicos demostraron la presencia de bacilos BCG. Una reacción eritematosa semejante ha sido descrita en la E. de Kawasaki. La evolución posterior, después de un año de efectuado el trasplante, se ha caracterizado por un incremento notable del desarrollo pondoestatural, con excelente estado general, evaluación inmunológica dentro de rangos normales y ausencia de episodios infecciosos.

(Palabras clave: Trasplante medular, inmunodeficiencia combinada severa, enfermedad de Kawasaki).

\section{Agradecimientos}

Los autores agradecen la cooperación recibióa por parte del equipo médico y paramédico de la Unidad de Traramiento Intensivo de la Cínica Alemana.

\section{Referencias}

1. Buckley RH: Advances in the diagnosis and treatment of immunodeficiency diseases. Arch Intern Med 1986; 146: 377.384 . 
2. Buckley RII: Immunodeficiency Discases. JAMA 1987; 25: $2841-2850$.

3. González B. Moreno $S$, Burdach $R$, Valenzuela MT: Clinical presentation of Bacillus Calmctte-Gucrin infections in patients with immunodeficiency syndromes. Pediatr Infect Dis J 1989: 8: 201-206.

4. Kenny A, litzig W: Bone marrow transplantarion for severe combined immunodeficiency discasc. Eur J Pediast 1979: 131: 155-177.

5. Gotti RA, Mewwissen JJ, Allen IID, Mong R, Good $R A$ : Immunological reconstitution of sex-linked lymphopentc immunological deficiency. Lance1 1968; 1: 1366.

6. Wijngendis L, Le Deist F, Griscelli $C$. Development of immunologic functions after marrow transplantation in 33 patients with severe combincd immunodeficiency Bjood 1989; 74: 2212-2219.

7. Boyum A: Separation of lymphocytes from blood and боле marrow. Scand J Lab Clin Invest $1968 ; 2$ l; 77 .

8. Mancini $G$, Carbonara $A$ and Heremans $F$ : Immunochernical quantitation of antigens by singlc radial im. murodifusion. Immunochem 1965: 2: 235 .

9. Giksti $G$ : Adenosine deaminase. In Bergmeyer, H.C.
Edit. Mcthods of enrymalic analysis. New York Academic Press Inc. 1974; 1092-1099.

10. Fischer A. Griscelli $C$. Friedrich $W$ : Bone marrow transplantation for immunodeficiencies and osteopetrosis: Europcan survey 1968-1986. I ancet 1986: 2; 1080-1084.

11. Wamer J, Dennerl $G$ : Bone martow graft rejeclion as a function of antibody-directed natural killer cells. J Exp Med 1985; 161: 563

12. Murphy W, Kumar V, Bennell $M$ : Aculc rejection of murine bone marrow allografts by natural killer cells and T cells. J Exp Med 1987; 166: 1499-1509.

13. Simmonsen $M$ : Graft versus host reactions: Their natural history and applicability as tools of research. Prog Allergy 1962; 6: 349.

14. Sanders J, Buckner $C D$, Bensinger WI, Levy W, Chard $R$ : Expericnce with marrow harvesting from donors less than two ycars of oge. Bone Marrow Transplantation $1987 ; 2: 45$

15. Bortin MM, Buckner CD: Major Complications of Manow Harvesing for Transplantation. Exp Hetnatol 1983; 11: 916.

16. Kawasaki T, Kawasaki disease Cardjol Young 1991; 1: 184-191. 